Julie Bernhardt, $\mathrm{PhD}$

Leonid Churilov, PhD

Fiona Ellery, BAppSci

(Nurs)

Janice Collier, $\mathrm{PhD}$

Jan Chamberlain,

GDipEd

Peter Langhorne, PhD

Richard I. Lindley, MD

Marj Moodie, DrPH

Helen Dewey, PhD

Amanda G. Thrift, PhD

Geoff Donnan, MD

On behalf of the AVERT

Collaboration Group

Correspondence to

Dr. Bernhardt:

julie.bernhardt@florey.edu.au

Editorial, page 2120

Supplemental data at Neurology.org

\title{
Prespecified dose-response analysis for A Very Early Rehabilitation Trial (AVERT)
}

OPEN

\section{ABSTRACT}

Objective: Our prespecified dose-response analyses of A Very Early Rehabilitation Trial (AVERT) aim to provide practical guidance for clinicians on the timing, frequency, and amount of mobilization following acute stroke.

Methods: Eligible patients were aged $\geq 18$ years, had confirmed first (or recurrent) stroke, and were admitted to a stroke unit within 24 hours of stroke onset. Patients were randomized to receive very early and frequent mobilization, commencing within 24 hours, or usual care. We used regression analyses and Classification and Regression Trees (CART) to investigate the effect of timing and dose of mobilization on efficacy and safety outcomes, irrespective of assigned treatment group.

Results: A total of 2,104 patients were enrolled, of whom 2,083 (99.0\%) were followed up at 3 months. We found a consistent pattern of improved odds of favorable outcome in efficacy and safety outcomes with increased daily frequency of out-of-bed sessions (odds ratio [OR] 1.13, 95\% confidence interval [Cl] 1.09 to $1.18, p<0.001)$, keeping time to first mobilization and mobilization amount constant. Increased amount (minutes per day) of mobilization reduced the odds of a good outcome (OR 0.94, 95\% Cl 0.91 to 0.97, $p<0.001$ ). Session frequency was the most important variable in the CART analysis, after prognostic variables age and baseline stroke severity.

Conclusion: These data suggest that shorter, more frequent mobilization early after acute stroke is associated with greater odds of favorable outcome at 3 months when controlling for age and stroke severity.

Classification of evidence: This study provides Class III evidence that shorter, more frequent early mobilization improves the chance of regaining independence after stroke. Neurology ${ }^{\circledast} 2016 ; 86: 2138-2145$

\section{GLOSSARY}

AVERT $=$ A Very Early Rehabilitation Trial; CART = Classification and Regression Tree; $\mathbf{C l}=$ confidence interval; IQR $=$ interquartile range; $\mathbf{m R S}$ = modified Rankin Scale; NIHSS = NIH Stroke Scale; OR = odds ratio; ROC = receiver operating characteristic; rtPA = recombinant tissue plasminogen activator; SAE = serious adverse event; TTFM = time from stroke onset to first mobilization out of bed; VEM = very early mobilization.

In our primary intention-to-treat analysis for A Very Early Rehabilitation Trial (AVERT), we reported that patients randomized to usual care had greater odds of a favorable outcome (modified Rankin Scale [mRS] score 0-2) at 3 months compared to those receiving the very early mobilization (VEM) protocol. ${ }^{1}$ However, a recommendation of "usual care" is of limited value to clinicians seeking guidance, as usual care was not standardized and mobilization often commenced within 24 hours of stroke. Importantly, "early" does not encapsulate all aspects of the interventions delivered in this trial. The VEM protocol was earlier, more frequent, and higher amounts of out-of-bed activity, ${ }^{2}$ a "complex intervention,"3 which was consistent with practices

From The Florey Institute of Neuroscience and Mental Health (J.B., L.C., F.E., J. Collier, J. Chamberlain, H.D., G.D.), La Trobe University (J.B.), Melbourne, Australia; Institute of Cardiovascular and Medical Sciences (P.L.), University of Glasgow, UK; George Institute for Global Health and Westmead Hospital Clinical School (R.I.L.), University of Sydney; Deakin Health Economics (M.M.), Faculty of Health, Deakin University, Burwood; and Eastern Health Clinical School, Faculty of Medicine, Nursing and Health Sciences (H.D.), and Stroke and Ageing Research Group, Department of Medicine, School of Clinical Sciences at Monash Health (A.G.T.), Monash University, Clayton, Australia.

Coinvestigators are listed on the Neurology ${ }^{\circledR}$ Web site at Neurology.org.

Go to Neurology.org for full disclosures. Funding information and disclosures deemed relevant by the authors, if any, are provided at the end of the article. The Article Processing Charge was funded by NIHR.

This is an open access article distributed under the terms of the Creative Commons Attribution License 4.0 (CC BY), which permits unrestricted use, distribution, and reproduction in any medium, provided the original work is properly cited. 
associated with better outcome in Norway. ${ }^{4}$ Greater amounts of physical training poststroke is associated with improved outcomes (without harm) in a number of metaanalyses, 5,6 and many guidelines recommend increasing training dose. Increased frequency, a critical intervention characteristic, was supported by 2 lines of evidence. Exercise benefits in sedentary adults, accumulated in multiple, short bouts, appear equivalent to a single, longer bout, ${ }^{7,8}$ and bursts of training appear highly suited to acute stroke patients. Further, frequent repetition of training (distributed practice) is associated with improved motor learning after stroke. ${ }^{9,10}$ In AVERT, all interventions were carefully recorded, thus allowing a detailed investigation of dose response. Our aim for these prespecified dose-response analyses ${ }^{11}$ is to provide practical guidance for clinicians.

The trial is registered with the Australia and New Zealand Clinical Trial Registry (ACTRN12606000185561).

METHODS Detailed methods are described elsewhere. ${ }^{1,11}$ In brief, AVERT, conducted in 56 stroke units in 5 countries, is a pragmatic, parallel-group, randomized controlled trial. Patients with ischemic or hemorrhagic stroke, admitted within 24 hours of onset, were eligible. Patients with early deterioration, another serious illness, unstable coronary conditions, not rousable to voice, or failing physiologic screening criteria were excluded. Patients or their nominated representative provided written consent. Randomization was blocked, balanced by site, and stratified by stroke severity. All trial personnel were masked to group, except the intervention monitor.

Standard protocol approvals, registrations, and patient consents. Ethical approval was obtained from relevant site institutional boards.

Procedures. Patients were randomized to receive either usual care or frequent out-of-bed activity (mobilization) in addition to usual care (VEM). ${ }^{1,11}$ VEM patients commenced mobilization within 24 hours of stroke and trained physiotherapy and nursing staff helped them continue taskspecific out-of-bed activity, targeting recovery of active sitting, standing, and walking activity, at a frequency and intensity (amount) guided by an intervention protocol. Functional ability at baseline, monitored daily and adjusted with recovery, guided the intervention dose with 4 titrations specified. For example, in low arousal, dependent patients (level 1), active sitting with assistance was the mobilization target, with each session lasting a minimum of 10 and maximum of 30 minutes. With higher-functioning patients (level 4), standing and walking were likely targets, each session again lasting a minimum of 10 minutes with no restricted maximum (patient-dependent). The frequency of sessions per day also varied according to functional level. Importantly, passive sitting (resting in a chair) was not classified as a VEM mobilization activity and sitting for more than 50 minutes at one time was discouraged. Intervention lasted 14 days or until discharge, whichever was sooner. Physiotherapists and nurses, with separate intervention targets, worked together to deliver the intervention dose. All mobilization activities were recorded online.

Outcome measures. Our primary outcome was a favorable outcome on the modified Rankin Scale (mRS 0-2) at 3 months poststroke. ${ }^{1}$ Secondary outcomes were time (days) to achieve unassisted walking over 50 meters, the proportion of patients achieving unassisted walking by 3 months, death, and the number of serious adverse events (SAEs) at 3 months. Immobilityrelated SAEs (deep venous thrombosis, pulmonary emboli, pressure sores, chest infections, urinary tract infections) and neurologic SAEs (stroke progression, recurrent stroke) were examined separately.

Dose measures. The dose-response analyses examine the 3 main characteristics of dose: (1) time from stroke onset to first mobilization out of bed (TTFM, hours), (2) median number of out-of-bed sessions per patient per day (frequency), and (3) median minutes of out-of-bed activity per patient per day (daily amount). Total minutes of out-of-bed activity over the intervention period (total amount) accounts for varying lengths of hospital stay.

Nurses recorded type of activity and time of the day each activity began, but not minutes, as this was not routine practice. Physiotherapists recorded activity type, time the activity began, and total out-of-bed activity time (minutes), consistent with their routine practice. Consequently, daily amount (minutes) and total amount (minutes) of out-of-bed activity reflect physiotherapy data alone, while TTFM and frequency of mobilizations is derived from both nurse and physiotherapist data. Episodes of sitting, standing, or walking activity separated from another episode of activity by $>5$ minutes of rest (e.g., in a chair) constituted 2 separate mobilizations. Active time (minutes), e.g., practicing sitto-stand from the chair, was recorded by the physiotherapist.

Statistical analysis. These dose-response analyses repeat our major primary and secondary analyses ${ }^{1}$ with dose characteristics (TTFM, frequency, daily amount, total amount) as independent variables, and were prespecified in our statistical analysis plan. ${ }^{11}$ To avoid excessive collinearity between daily amount and total amount, we tested 2 separate models, adjusted for age and baseline stroke severity (NIH Stroke Scale [NIHSS]), for all analyses, as follows:

1. Model 1: TTFM, median daily number of out-of-bed sessions (frequency), median daily out-of-bed session time (in 5minute increments).

2. Model 2: TTFM, median daily number of out-of-bed sessions (frequency), total minutes in out-of-bed activity over the intervention period (in 5-minute increments).

The primary analysis, with favorable outcome ( $\mathrm{mRS} 0-2)$ at 3 months as the dependent variable, was conducted using binary logistic regression models.

The dose effect on the odds of achieving unassisted walking by 3 months was investigated using binary logistic regression analyses (effect sizes: adjusted odds ratios [ORs] and $95 \%$ confidence intervals $[\mathrm{CI} s]$ ) while the time (days) to achieve unassisted walking (censored at 3 months) was assessed using Cox regression analyses (adjusted hazard ratios with 95\% CIs).

We analyzed mortality outcomes using binary logistic regression with death at 3 months (mRS 6) as the dependent variable (effect sizes: adjusted ORs with 95\% CIs). We investigated dose effect on counts of SAEs using negative binomial regression 
(effect sizes: adjusted incidence rate ratios with 95\% CIs). Immobility-related and neurologic SAEs were analyzed separately.

We used Classification and Regression Tree (CART) advanced analysis (Salford Predictive Modeler Software Suite version 7, Salford Systems, San Diego, CA) to further investigate the complex interactions between patient and dose characteristics and favorable outcome. CART is a binary partitioning statistical method that starts with the total sample and, in a stepwise manner, splits the sample into subsamples that are homogenous with respect to a defined outcome. ${ }^{12}$ The input variable that achieves the most effective split is dichotomized by automated analysis at an optimal threshold, maximizing the homogeneity within, and separation between, resulting subgroups. To maximize model performance (assessed by area under the receiver operating characteristic [ROC] curve), a 10-fold internal cross-validation, where data are randomly divided into 10 groups with 9 used to build the model (training) and 1 used to validate (testing), is performed. In addition to the classification tree, CART numerically ranks each input used to build the tree by relative importance.

Our CART1 (figure 1) analysis included all prespecified subgroup variables $^{1}$ (age, NIHSS, stroke type, recombinant tissue plasminogen activator [rtPA] treatment), group allocation, and the 3 dose characteristics (TTFM, frequency, and daily amount). We explored the relative importance of each variable to achieving a favorable outcome (mRS 0-2). CART2 (figure e-1 on the Neurology ${ }^{\circledR}$ Web site at Neurology.org) was used to investigate multidimensional relationships between dose characteristics alone and favorable outcome.

RESULTS Between July 18, 2006, and October 16, 2014, we randomly assigned 2,104 patients to VEM $(\mathrm{n}=1,054)$ and usual care $(\mathrm{n}=1,050)$, with 2,083 (99\%) patients followed to the primary 3-month endpoint. This group constitutes the dataset for all analyses in this article. In total, $25 \%$ were over 80 years of age, few were disabled prior to stroke, more than $43 \%$ of patients experienced a moderate to severe stroke (NIHSS $>7$ ), and $12 \%$ were diagnosed with intracerebral hemorrhage (table 1). A total of 1,584 patients (75\%) had no disability (premorbid mRS 0) prior to stroke, a further 519 (24\%) had slight disability (mRS $1-2$ ), and 1,833 $(87 \%)$ could walk without aids. The median (interquartile range $[\mathrm{IQR}]$ ) time to first mobilization was 20.2 hours (14.7-23.8), while $1,588(75 \%)$ participants commenced out-of-bed activity within 24 hours of stroke (table 2).

Greater TTFM was associated with a reduced odds of favorable outcome $(0.99,0.98-1.00, p=0.036$; table 3). In model 1 (favorable outcome), the effect of TTFM was adjusted for median daily number of sessions (frequency), median daily minutes (daily amount), age, and baseline NIHSS. In this example, the significant effect for TTFM on the odds of a favorable outcome should be interpreted as follows: for 2 patients of similar age and stroke severity, receiving a similar frequency and daily amount of out-of-bed activity, the patient who starts mobilization earlier has improved odds of a favorable outcome.
For efficacy outcomes, favorable outcome (mRS 0-2) and walking by 3 months, we found a similar pattern of association with each of the dose characteristics, and all associations were significant (table 3). In model 1, TTFM, frequency, and daily amount all significantly influenced the odds of a favorable outcome. Keeping TTFM and frequency constant, every extra 5 minutes of out-of-bed activity per day reduced the odds of a favorable outcome. Increasing the frequency of sessions improved the odds of favorable outcome by 13\% (95\% CI 9-18 $p<0.001)$ and improved the odds of walking 50 meters unassisted by $66 \%$ (95\% CI 53-80, $p<$ $0.001)$ when TTFM and daily amount were kept constant. This pattern was similar in model 2.

When examining associations with intervention characteristics and death, increasing session frequency was the only characteristic that reduced the odds of death by approximately $20 \%$ (table 4 ). Nonfatal SAEs showed less consistent associations between dose characteristics and outcome. TTFM was not significant in any model, but frequency and amount were (table 4). Given the relatively few immobility and neurologic SAEs, these results should be viewed with caution.

In CART1 (figure 1), including TTFM, frequency and daily amount, age, NIHSS, stroke subtype, rtPA treatment, and randomization group, we found good to excellent performance, with a training ROC of 0.78 and a testing ROC of 0.77 . The relative contribution of variables to the model showed initial stroke severity (NIHSS), a known predictor of recovery, was most important (100\%), followed by session frequency $(39.2 \%)$, age (32.4\%), TTFM $(10.5 \%)$, and daily amount (2.7\%). Treatment group was not an important discriminator.

Younger patients ( $\leq 76.3$ years) and those with low NIHSS score $(\leq 7.5)$ had high probability of a favorable outcome (78.2\%). Those with NIHSS score $>7.5$ showed low (21.3\%) probability of achieving little to no disability (mRS $0-2$ ). The influence of intervention characteristics becomes evident as we move farther down the tree. For example, at terminal node 4 (figure 1), patients between 76.3 and 86.1 years, with an NIHSS score $>4.5$ (but $\leq 7.5$ ), showed greater probability of a favorable outcome $(63.6 \%)$ if they received no more than 13.5 minutes per day distributed across frequent (short) sessions. Frequency again split the tree for terminal nodes 5 and 6 , indicating that more frequent sessions to achieve a higher dose ( $>13.5$ minutes per day) was associated with greater odds of a good outcome. CART2 (figure e-1) explores the influence of dose variables on outcome. Further exploration of CART1 large terminal nodes 1 (younger age) and 8 (more severe stroke) are shown in figures e-2 and e-3. TTFM, frequency, amount, and group are all influential splitters in these models. 
Figure 1 Classification and Regression Tree (CART) advanced analysis investigating interactions between dose and patient characteristics and odds of a favorable outcome (modified Rankin Scale [mRS] 0-2)

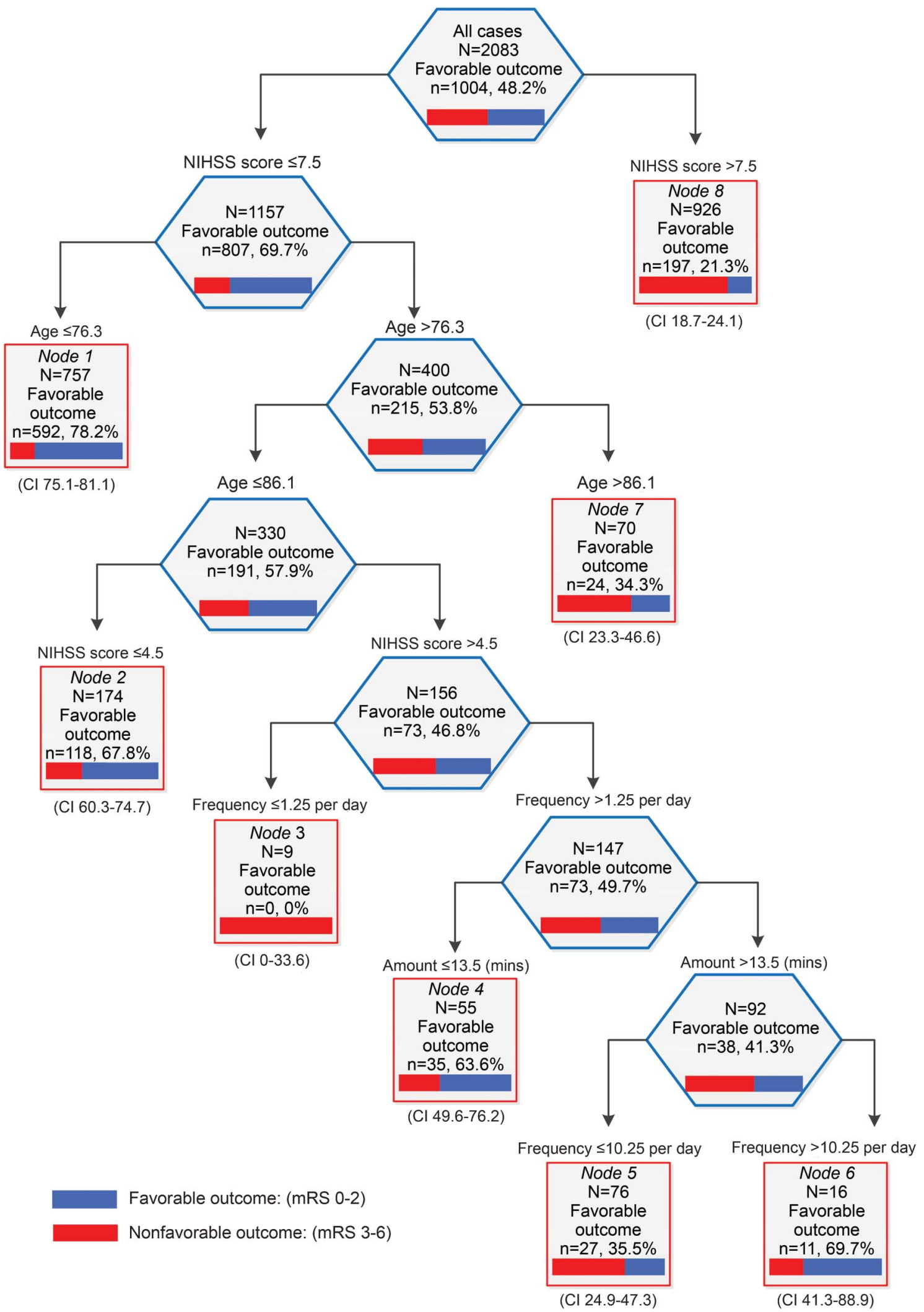

Time to first mobilization, median daily number of out-of-bed sessions per day (frequency), median daily out-of-bed activity session time (amount), age (in years), and stroke severity (NIH Stroke Scale [NIHSS]). Frequency is derived from nursing and physiotherapist data. Amount (minutes) is derived from physiotherapist data only. $\mathrm{Cl}=$ confidence interval. 
Table 1 Baseline characteristics of all patients

All patients $(n=2,104)$

Recruitment region, $\mathrm{n}(\%)$

Australia/New Zealand

$1,243(59)$

Asia

251 (12)

United Kingdom

$610(29)$

Patient details

Age, y, median (IQR)

72.5 (62.9-80.3)

Female

$818(40)$

Risk factors, $n$ (\%)

Hypertension

Ischemic heart disease

$1,424(68)$

Hypercholesterolemia

487 (23)

929 (40)

Diabetes mellitus

467 (22)

Atrial fibrillation

466 (22)

Smoking, n (\%)

Never smoked

945 (45)

Smoker ${ }^{\mathrm{a}}$

431 (20)

Ex-smoker

Unknown

$693(33)$

35 (2)

Living arrangement at time of admission

Home alone/with someone, n (\%)

$532(25) / 1,542(73)$

Time (in hours) to randomization, median (IQR)

$18.2(12.3-21.8)$

First stroke, n (\%)

$1,721(82)$

NIHSS score

Median (IQR)

7 (4-12)

Mild (NIHSS 1-7), n (\%)

$1,170(56)$

Moderate (NIHSS 8-16), n (\%)

643 (31)

Severe (NIHSS > 16), n (\%)

$291(14)$

Stroke type (Oxfordshire Stroke Classification), $\mathrm{n}(\%)$

$\mathrm{TACl}$

456 (22)

PACI

668 (32)

POCI

199 (9)

$\mathrm{LACl}$

$523(25)$

$\mathrm{ICH}$

258 (12)

Treated with rtPA

507 (24)

Baseline walking (MSAS), $\mathrm{n}(\%)$

Independent

855 (41)

Supervised or assisted

$1,060(50)$

Abbreviations: ICH = intracerebral hemorrhage; IQR = interquartile range; $\mathrm{LACl}=$ lacunar infarct; $\mathrm{mRS}=$ modified Rankin Scale; MSAS = Mobility Scale for Acute Stroke ${ }^{13}$ walking score; $\mathrm{NIHSS}=\mathrm{NIH}$ Stroke Scale; $\mathrm{PACl}=$ partial anterior circulation infarct; $\mathrm{POCl}=$ pos terior circulation infarct; rtPA = recombinant tissue plasminogen activator; $\mathrm{TACl}=$ total anterior circulation infarct.

${ }^{\text {a }}$ Current smoker, or quitting in the last 2 years.

${ }^{\mathrm{b}}$ Quitting $>2$ years ago. intervention characteristics irrespective of treatment group. In particular, we saw $13 \%$ improvement in the odds of a favorable outcome with each additional session of out-of-bed activity per day (keeping the time to first mobilization and daily amount constant). Conversely, increasing the amount of time spent in out-of-bed activity, keeping the frequency and time to first mobilization constant, reduced the odds of a favorable outcome. The potentially beneficial effect of increasing the frequency of out-of-bed activity (but not the amount) was consistent across most of the efficacy and safety analyses.

These findings begin to unpack the primary results, where we reported that VEM (very early, frequent, and higher-dose out-of-bed activity) reduced the odds of a favorable outcome at 3 months. ${ }^{1}$ This dose-response analysis suggests that increased frequency of mobilization (keeping other intervention characteristics constant) helps reduce disability and increases the odds of walking by 3 months and reduces the odds of death. However, increasing the minutes of out-of-bed activity was more likely to result in worse outcomes. In other words, these findings indicate that short, frequent sessions may be preferable for many patients in the first weeks after stroke.

Addition of the CART analyses provided further support for the important influence of session frequency on outcome. Even with the inclusion of patient characteristics considered strongly predictive of outcome after stroke (such as stroke severity and age), intervention characteristics played an explicit and important role, defining homogenous groups of patients based on their chances of achieving the favorable outcome. Indeed, in patients with more severe stroke (NIHSS > 13.5), a more favorable outcome was evident in those with more rather than less sessions (figure e-3). In humans and animals, there is limited discussion about the potential effect of frequency of intervention on stroke outcome. Recently, Bell et al. ${ }^{14}$ studied skilled reaching in stroke-affected mice and found that twice daily, higher-dose training accelerated recovery and improved final outcome compared to a once-a-day, lower-dose regimen. In humans, a number of systematic reviews and metaanalyses suggest a dose-response relationship, with more intensive therapy resulting in improved functional outcome after stroke., ${ }^{5,6,15}$ Definitions for therapy intensity vary, but to date the focus has been on amount (minutes) rather than frequency (repetitions of a task, or sessions per day). ${ }^{16}$ Generally, inadequate reporting of therapy interventions, together with significant heterogeneity in the timing, amount, frequency, and intensity of training provided, complicates messaging of poststroke therapy, particularly in the first few weeks, where few studies exist. ${ }^{17}$

DISCUSSION We found a consistent pattern of association between the odds of experiencing little or no disability (mRS 0-2) at 3 months and the 


\section{Table 2 Intervention summary, all patients}

\section{Characteristics}

Time to first mobilization, $\mathrm{h}$

Frequency per person ${ }^{b}$ (median daily sessions of out-of-bed activity)

Daily amount per person ${ }^{\mathrm{c}}$ (median minutes per day spent in out-of-bed activity)

Total amount per person ${ }^{\mathrm{c}}$ (minutes over the intervention period ${ }^{d}$ )
All patients $(n=2,104)$, median (IQR)

20.2 (14.7-23.8); $n=2,078 ;$ missing $^{a}=26$

5 (3-8)

$17.5(6-35)$

$120(50-235)$
Abbreviation: IQR = interquartile range.

Median estimates include days when time or number of out-of-bed sessions $=0$; i.e., the patient was recorded as not getting up on that day.

a Missing: Hours to first mobilization $(n=26)$; these patients were never mobilized, due to an early serious adverse event $(n=13)$, decision to palliate $(n=5)$, or early death $(n=5)$, transfer from the stroke unit $(n=1)$, or drop-out $(n=1)$. For these patients, therapy and nurse recording forms were completed throughout their stroke unit stay, with zero time and zero sessions.

${ }^{b}$ Frequency is derived from nursing and physiotherapist data.

${ }^{c}$ Amount (minutes) is derived from physiotherapist data only.

${ }^{d}$ Total amount of out-of-bed activity over the intervention period was estimated over the total length of stay or until 14 days poststroke (whichever occurred first).

Interestingly, a 3-arm early rehabilitation trial testing upper limb constraint regimens, although small ( $\mathrm{n}=$ 52), also found that a higher amount of training was inferior to lower-dose usual care. ${ }^{18} \mathrm{~A}$ critical challenge in rehabilitation is determining who should be targeted and when and what is the optimal intervention. ${ }^{19}$

The influence of time to first mobilization was less clear, partly due to a compact distribution pattern with the median time (IQR) less than 24 hours (14.7-23.8). The optimal time to commence outof-bed activity remains unknown. While early animal studies showed that very-high-dose training within the first days poststroke increased brain lesion volume, ${ }^{20}$ our recent animal meta-analysis ${ }^{21}$ found that a shorter interval between stroke and exercise start reduced infarct volume (effect size $-0.24,95 \% \mathrm{CI}$ -0.36 to $-0.06, p<0.004)$, without significantly influencing behavioral outcomes. ${ }^{21} \mathrm{~A}$ further animal systematic review showed that early initiated (24-48 hours poststroke) moderate exercise reduced lesion volume and protected perilesional tissue against oxidative damage and inflammation. ${ }^{22}$ Given that animal research to date suggests that activity within 24-48 hours of ischemic stroke onset may be helpful, an obvious translation gap exists.

Study strengths include that the dose-response analysis was prespecified ${ }^{11}$ to help understand our complex intervention, and we had a strong focus on the quality of the nurse and physiotherapy data collected in the trial. ${ }^{11}$ Our main limitation is that this exploratory analysis is not an RCT testing each of the intervention components separately (time, amount, frequency). Our results will need to be confirmed in further RCTs. Because we recorded physiotherapist-assisted out-of-bed therapy time only (not nursing), these data underestimate the actual minutes each day that a patient spent undertaking out-of-bed activity.

Table 3 Effect of intervention characteristics on favorable outcome (mRS 0-2) and unassisted walking

\begin{tabular}{|c|c|c|c|c|c|c|}
\hline \multirow[b]{2}{*}{ Efficacy } & \multicolumn{2}{|c|}{ Favorable outcome (mRS 0-2) } & \multicolumn{4}{|c|}{ Walking unassisted 50 meters } \\
\hline & OR (95\% CI) & p Value & Binary OR (95\% Cl) & p Value & Cox hazard ratio $(95 \% \mathrm{Cl})$ & p Value \\
\hline \multicolumn{7}{|l|}{ Model 1} \\
\hline $\begin{array}{l}\text { Time to first mobilization } \\
\text { (per extra hour) }\end{array}$ & $0.99(0.98-1.0)$ & 0.036 & $1.0(0.99-1.0)$ & 0.40 & $0.99(0.98-0.99)$ & $<0.001$ \\
\hline $\begin{array}{l}\text { Frequency, median daily sessions } \\
\text { (per one extra session) }\end{array}$ & $1.13(1.09-1.18)$ & $<0.001$ & $1.66(1.53-1.80)$ & $<0.001$ & $1.10(1.09-1.13)$ & $<0.001$ \\
\hline $\begin{array}{l}\text { Daily amount, median } \\
\text { (per extra } 5 \text { minutes) }\end{array}$ & $0.94(0.91-0.97)$ & $<0.001$ & $0.85(0.81-0.89)$ & $<0.001$ & $0.96(0.94-0.97)$ & $<0.001$ \\
\hline \multicolumn{7}{|l|}{ Model 2} \\
\hline $\begin{array}{l}\text { Time to first mobilization } \\
\text { (per extra hour) }\end{array}$ & 0.99 (0.98-1.0) & 0.025 & $1.0(0.99-1.0)$ & 0.48 & $0.99(0.98-0.99)$ & $<0.001$ \\
\hline $\begin{array}{l}\text { Frequency, median daily sessions }{ }^{a} \\
\text { (per one extra session) }\end{array}$ & $1.14(1.10-1.18)$ & $<0.001$ & $1.63(1.51-1.76)$ & $<0.001$ & $1.11(1.10-1.13)$ & $<0.001$ \\
\hline $\begin{array}{l}\text { Total amount }{ }^{b} \text { (per extra } 5 \text { minutes } \\
\text { over intervention period) }\end{array}$ & $0.99(0.98-0.99)$ & $<0.001$ & $0.98(0.98-0.99)$ & $<0.001$ & 0.99 (0.99-0.99) & $<0.001$ \\
\hline
\end{tabular}

Abbreviations: $\mathrm{Cl}=$ confidence interval; $\mathrm{mRS}=$ modified Rankin Scale; OR = odds ratio.

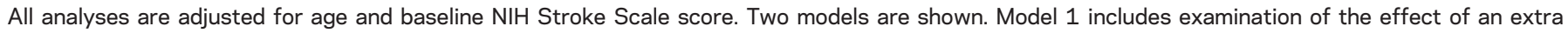

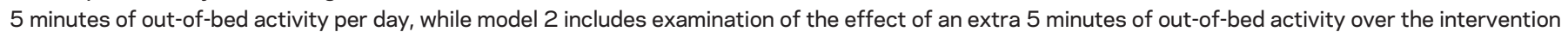

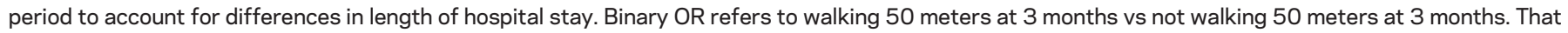

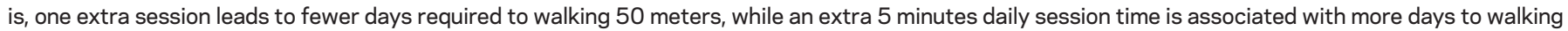
50 meters.

${ }^{a}$ Frequency is derived from nursing and physiotherapist data.

${ }^{\mathrm{b}}$ Amount (minutes) is derived from physiotherapist data only. 
Table 4 Effect of intervention characteristics on death and nonfatal serious adverse events

\begin{tabular}{|c|c|c|c|c|c|c|c|c|}
\hline & \multicolumn{8}{|l|}{ Safety } \\
\hline & \multicolumn{2}{|l|}{ Deaths } & \multicolumn{2}{|l|}{ Nonfatal SAEs } & \multicolumn{2}{|l|}{$\begin{array}{l}\text { Fatal or nonfatal } \\
\text { neurologic SAEs }\end{array}$} & \multicolumn{2}{|l|}{$\begin{array}{l}\text { Fatal or nonfatal } \\
\text { immobility SAEs }\end{array}$} \\
\hline & Binary OR (95\% Cl) & $p$ Value & IRR (95\% CI) & $p$ Value & IRR (95\% CI) & $p$ Value & IRR (95\% CI) & $p$ Value \\
\hline \multicolumn{9}{|l|}{ Model 1} \\
\hline $\begin{array}{l}\text { Time to first mobilization } \\
\text { (per extra hour) }\end{array}$ & $0.99(0.98-1.00)$ & 0.07 & $1.0(0.99-1.00)$ & 0.71 & $1.0(0.99-1.00)$ & 0.45 & $1.00(0.99-1.00)$ & 0.59 \\
\hline $\begin{array}{l}\text { Frequency, median daily sessions }{ }^{a} \\
\text { (per one extra session) }\end{array}$ & $0.78(0.70-0.88)$ & $<0.01$ & $0.99(0.95-1.03)$ & 0.55 & $0.89(0.84-0.95)$ & 0.001 & $0.94(0.87-1.01)$ & 0.11 \\
\hline $\begin{array}{l}\text { Daily amount, median' } \\
\text { (per extra } 5 \text { minutes) }\end{array}$ & $0.96(0.89-1.04)$ & 0.30 & $0.96(0.93-0.99)$ & 0.01 & $1.03(0.99-1.08)$ & 0.17 & $0.94(0.89-1.00)$ & 0.06 \\
\hline \multicolumn{9}{|l|}{ Model 2} \\
\hline $\begin{array}{l}\text { Time to first mobilization } \\
\text { (per extra hour) }\end{array}$ & $0.99(0.98-1.00)$ & 0.07 & $0.99(0.99-1.00)$ & 0.81 & $1.00(0.99-1.00)$ & 0.35 & $1.00(0.99-1.00)$ & 0.59 \\
\hline $\begin{array}{l}\text { Frequency, median daily sessions }{ }^{a} \\
\text { (per one extra session) }\end{array}$ & $0.79(0.71-0.88)$ & $<0.01$ & $0.96(0.93-0.99)$ & 0.02 & $0.93(0.88-0.98)$ & $<0.01$ & $0.91(0.85-0.97)$ & $<0.01$ \\
\hline $\begin{array}{l}\text { Total amount }{ }^{\mathrm{b}} \text { (per extra } 5 \text { minutes } \\
\text { over intervention period) }\end{array}$ & $0.99(0.98-1.00)$ & 0.06 & $1.00(1.00-1.00)$ & 0.49 & $1.00(0.99-1.00)$ & 0.32 & $1.0(0.99-1.00)$ & 0.41 \\
\hline
\end{tabular}

Abbreviations: $\mathrm{Cl}=$ confidence interval; IRR = incident rate ratio; $\mathrm{OR}=$ odds ratio; $\mathrm{SAE}=$ serious adverse event.

All analyses are adjusted for age and baseline NIH Stroke Scale score. Two models are shown. Model 1 includes examination of the effect of an extra 5 minutes of out-of-bed activity per day, while model 2 includes examination of the effect of an extra 5 minutes of out-of-bed activity over the intervention period to account for differences in length of hospital stay. Immobility-related SAEs included deep vein thrombosis, pulmonary embolism, pressure sores, pneumonia, and urinary tract infection. Neurologic SAEs include stroke progression and recurrent stroke.

${ }^{\text {a }}$ Frequency is derived from nursing and physiotherapist data.

${ }^{\mathrm{b}}$ Amount (minutes) is derived from physiotherapist data only.

One could argue that the intervention protocol influenced our findings because intervention dose was greater when participants had a less severe stroke. However, given that we found the same relationship between time to first mobilization, frequency, and amount of time in the usual care group alone as found for the whole group, this seems unlikely. That is, more frequent sessions (keeping mobilization time and median minutes of out-of-bed activity per day constant) improved the odds of a good outcome by $12 \%$ (OR 1.12, 95\% CI 1.04-1.21, $p<0.004$ ). Interestingly, less time to first mobilization was also associated with improved odds of a good outcome (OR 0.98, 95\% CI 0.97-0.99, $p=0.002$ ), while more minutes of out-of-bed activity was not (table e-1). Therefore, while the intervention protocol itself may have confounded some of this association, the results provide us with important clues on how the components of early and intensive rehabilitation affect outcome.

These results provide insights into the drivers of outcome and provide clinicians with a guide to early rehabilitation practices. There are 3 important messages from our results. The first is that physiotherapist- and nurse-facilitated mobility interventions delivered in the acute phase of care can change a patient's long-term outcomes, so it is critical that trialists carefully define and measure these interventions. Second, these results suggest that the frequency of intervention may be a more important driver of outcome. This has received little attention to date and requires further evaluation in future trials. The final message is that the currently accepted philosophy of "more practice is always better" needs to be reconsidered, particularly within the first days after stroke. The issue of timing, frequency, and amount of therapy is more complex that previously realized. This represents fertile ground for future research.

\section{AUTHOR CONTRIBUTIONS}

J. Bernhardt conceived and designed the study, wrote the first draft of the manuscript, and approved the final version. L. Churilov was the study statistician who prepared the analyses, reviewed the manuscript, and provided input. F. Ellery prepared the CART figures, reviewed the manuscript, and provided input. J. Collier reviewed the manuscript and provided input. J. Chamberlain reviewed the manuscript and provided input. P. Langhorne reviewed the manuscript and provided input. R.I. Lindley reviewed the manuscript and provided input. M. Moodie reviewed the manuscript and provided input. H. Dewey reviewed the manuscript and provided input. A.G. Thrift reviewed the manuscript and provided input. G. Donnan reviewed the manuscript and provided input.

\section{ACKNOWLEDGMENT}

The authors thank the participants and their families; the AVERT Collaboration investigators; and Tara Purvis, the independent intervention monitor throughout the trial.

\section{STUDY FUNDING}

The trial was supported by the National Health and Medical Research Council (NHMRC) of Australia (project grant nos.: 386201, 1041401). Additional funding was received from Chest Heart and Stroke Scotland (Res08/A114), Northern Ireland Chest Heart and Stroke, 
Singapore Health (SHF/FG401P/2008), The Stroke Association, UK (TSA2009/09), and the National Institute of Health Research, UK (grant no.: HTA Project 12/01/16). The Florey Institute of Neuroscience and Mental Health received support from the Victorian government via the Operational Infrastructure Support Scheme. The content of the publication is solely the responsibility of the authors and does not reflect the views of the funders.

\section{DISCLOSURE}

J. Bernhardt reports fellowship funding from the NHMRC (105863), the Australia Research Council (0991086), and the National Heart Foundation; NHMRC and Stroke Association UK project grants; support to provide an overview of early mobilization research at a European Stroke Conference 2013 seminar sponsored by Ever Pharma Neuro Pharma GmbH; and travel support to attend the European Stroke Conference and World Stroke Conference. L. Churilov reports membership on 5 editorial boards. F. Ellery reports salary from NHMRC grants $(386201,1041401)$. J. Collier reports salary from NHMRC grants $(386201,1041401)$. J. Chamberlain reports salary from NHMRC grants $(386201,1041401)$. P. Langhorne reports funding from Chest Heart and Stroke Scotland (Res08/A114), The Stroke Association, UK (TSA 2009/09), and the National Institute of Health Research, UK (Grant No: HTA Project 12/01/16). R. Lindley reports receiving compensation from Boehringer Ingelheim for chairing a scientific committee, lecturing honoraria from Covidien and Pfizer, is Associate Editor for the Australasian Journal on Ageing, receives publishing royalties from 2 books, and has received various project grants from NHMRC. M. Moodie reports no disclosures. H. Dewey reports fellowship funding from the NHMRC (336102). A. Thrift reports fellowship funding from the NHMRC (1042600). G. Donnan reports membership on Boehringer Ingelheim, Seriver, Sanofi Aventis, and Bristol Myer Squibb scientific advisory boards and serves as Editor-in-Chief of International Journal of Stroke, as an advisory board member for Stroke, Journal of Neuroimaging, and Lancet Neurology, and is an editorial board member of Stroke Research and Treatment. Go to Neurology.org for full disclosures.

Received August 10, 2015. Accepted in final form January 12, 2016.

\section{REFERENCES}

1. Bernhardt J, Langhorne P, Lindley R, et al. Efficacy and safety of very early mobilisation within 24 hours of stroke onset (AVERT): a randomised controlled trial. Lancet 2015;386:46-55.

2. van Wijk R, Cumming T, Churilov L, Donnan G, Bernhardt J. An early mobilization protocol successfully delivers more and earlier therapy to acute stroke patients: further results from phase II of AVERT. Neurorehabil Neural Repair 2012;26:20-26.

3. Craig P, Dieppe P, Macintyre S, Michie S, Nazareth I, Petticrew M. Developing and evaluating complex interventions: the new Medical Research Council guidance. BMJ 2008;337:979-983.

4. Indredavik B, Bakke RPT, Slordahl SA, Rokseth R, Haheim LL. Treatment in a combined acute and rehabilitation stroke unit: which aspects are most important? Stroke 1999;30:917-923.

5. Veerbeek J, van Wegen E, Van Peppen RPS, et al. What is the evidence for physical therapy poststroke? A systematic review and meta-analysis. PLoS One 2014;9:e87987.

6. Kwakkel G, van Peppen RPS, Wagenaar R, et al. Effects of augmented exercise therapy time after stroke: a meta-analysis. Stroke 2004;35:2529-2536.
7. Macfarlane DJ, Taylor LH, Cuddihy TF. Very short intermittent vs continuous bouts of activity in sedentary adults. Prev Med 2006;43:332-336.

8. Murphy MH, Blair SN, Murtagh EM. Accumulated versus continuous exercise for health benefit: a review of empirical studies. Sports Med 2009;39:29-43.

9. Kitago T, Krakauer JW. Motor learning principles for neurorehabilitation. In: Barnes MP, Good DC, eds. Neurological Rehabilitation. New York: Elsevier; 2013.

10. Krakauer JW, Carmichael ST, Corbett D, Wittenberg GF. Getting neurorehabilitation right: what can be learned from animal models? Neurorehabil Neural Repair 2012; 26:923-931.

11. Bernhardt J, Churilov L, Dewey H, et al. Statistical analysis plan (SAP) for a very early rehabilitation trial (AVERT): an international trial to determine the efficacy and safety of commencing out of bed standing and walking training (very early mobilisation) within $24 \mathrm{~h}$ of stroke onset vs usual stroke unit care. Int J Stroke 2015;10:23-24.

12. James G, Witten D, Hastie T, Tibshirani R. An Introduction to Statistical Learning with Applications in R. 1st ed. New York: Springer Science + Business Media; 2013:303.

13. Simondson J, Goldie P, Brock K, Nosworthy J. The mobility scale for acute stroke patients: intra-rater and inter-rater reliability. Clin Rehab 1996;10:295-300.

14. Bell JA, Wolke ML, Ortez RC, Jones TA, Kerr AL. Training intensity affects motor rehabilitation efficacy following unilateral ischemic insult of the sensorimotor cortex in C57BL/6 mice. Neurorehabil Neural Repair 2015;29: 590-598.

15. Pollock A, Baer G, Campbell P, et al. Physical rehabilitation approaches for the recovery of function and mobility following stroke. Cochrane Database Syst Rev 2014;4: CD001920.

16. Kwakkel G. Impact of intensity of practice after stroke: issues for consideration. Disabil Rehabil 2006;28:823-830.

17. Billinger SA, Arena R, Bernhardt J, et al. Physical activity and exercise recommendations for stroke survivors: a statement for healthcare professionals from the American Heart Association/American Stroke Association. Stroke 2014;45:1-22.

18. Dromerick AW, Lang CE, Birkenmeirer RL, et al. Very early constraint-induced movement during stroke rehabilitation (VECTORS): a single-centre RCT. Neurology 2009;73:195-201.

19. Bernhardt J, Indredavik B, Langhorne P. When should rehabilitation begin after stroke? Int J Stroke 2013;8:5-7.

20. Humm JL, Kozlowski DA, James DC, Gotts JE, Schallert T. Use-dependent exacerbation of brain damage occurs during an early post-lesion vulnerable period. Brain Res 1998;783:286-292.

21. Egan K, Janssen H, Sena E, et al. Exercise reduces infarct volume and facilitates neurobehavioural recovery: a systematic review and meta-analysis of exercise models in ischaemic stroke. Neurorehabil Neural Repair 2014;28:800-812.

22. Austin MW, Ploughman M, Glynn L, Corbett D. Aerobic exercise effects on neuroprotection and brain repair following stroke: a systematic review and perspective. Neurosci Res 2014;87:8-15. 


\section{Neurology}

\section{Prespecified dose-response analysis for A Very Early Rehabilitation Trial (AVERT)}

Julie Bernhardt, Leonid Churilov, Fiona Ellery, et al.

Neurology 2016;86;2138-2145 Published Online before print February 17, 2016

DOI 10.1212/WNL.0000000000002459

This information is current as of February 17, 2016

Neurology ${ }^{\circledR}$ is the official journal of the American Academy of Neurology. Published continuously since 1951, it is now a weekly with 48 issues per year. Copyright Copyright (C) 2016 The Author(s). Published by Wolters Kluwer Health, Inc. on behalf of the American Academy of Neurology. All rights reserved. Print ISSN: 0028-3878. Online ISSN: 1526-632X.

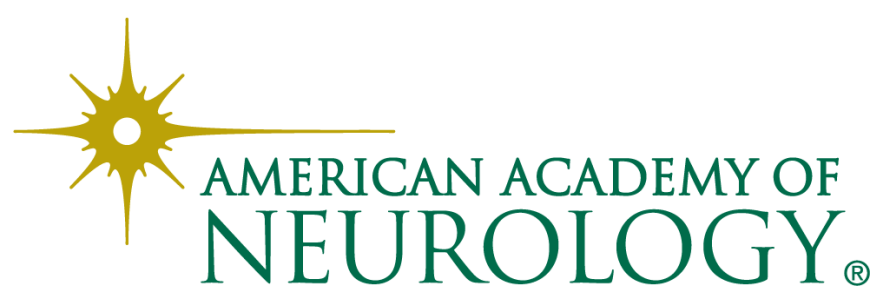




\section{Updated Information \& Services}

\section{Supplementary Material}

\section{References}

\section{Citations}

Subspecialty Collections

\section{Errata}

Permissions \& Licensing

\section{Reprints}

including high resolution figures, can be found at: http://n.neurology.org/content/86/23/2138.full

Supplementary material can be found at: http://n.neurology.org/content/suppl/2016/02/18/WNL.0000000000002 459.DC1

http://n.neurology.org/content/suppl/2016/02/18/WNL.0000000000002 459.DC2

http://n.neurology.org/content/suppl/2016/06/04/WNL.0000000000002 459.DC3

This article cites 20 articles, 4 of which you can access for free at: http://n.neurology.org/content/86/23/2138.full\#ref-list-1

This article has been cited by 2 HighWire-hosted articles: http://n.neurology.org/content/86/23/2138.full\#\#otherarticles

This article, along with others on similar topics, appears in the following collection(s):

All Cerebrovascular disease/Stroke

http://n.neurology.org/cgi/collection/all_cerebrovascular_disease_strok e

\section{All Clinical trials}

http://n.neurology.org/cgi/collection/all_clinical_trials

All Rehabilitation

http://n.neurology.org/cgi/collection/all_rehabilitation

Class III

http://n.neurology.org/cgi/collection/class_iii

Clinical trials Randomized controlled ( $\overline{C O N S O R T}$ agreement)

http://n.neurology.org/cgi/collection/clinical_trials_randomized_control led_consort_agreement

An erratum has been published regarding this article. Please see next page or:

/content/89/1/107.2.full.pdf

Information about reproducing this article in parts (figures,tables) or in its entirety can be found online at:

http://www.neurology.org/about/about_the_journal\#permissions

Information about ordering reprints can be found online:

http://n.neurology.org/subscribers/advertise

Neurology ${ }^{\circledR}$ is the official journal of the American Academy of Neurology. Published continuously since 1951, it is now a weekly with 48 issues per year. Copyright Copyright ( 2016 The Author(s). Published by Wolters Kluwer Health, Inc. on behalf of the American Academy of Neurology. All rights reserved. Print ISSN: 0028-3878. Online ISSN: 1526-632X.

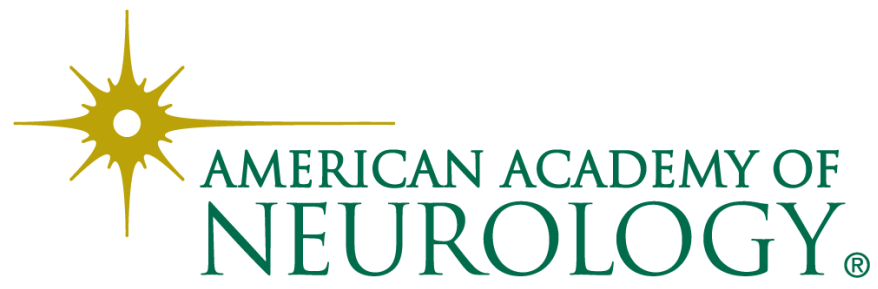


Section Editor

Robert C. Griggs, MD
Editors' Note: Commenting on "Long-term cortisol measures predict Alzheimer disease risk," Drs. Lattanzi and Silvestrini point out the interrelationships among cortisol dysregulation, insulin resistance, and blood pressure variability in Alzheimer disease $(A D)$ and suggest that the authors study the association between cortisol exposure and the risk of nonAD dementias. Dr. Onofrj critiques "Mediodorsal nucleus and its multiple cognitive functions" because it omitted discussion of confabulations. He also shares a case he described with confabulations due to isolated bilateral lacunes of mediodorsal nuclei. Golden et al., authors of the study, agree and suggest a possible laterality to the role of the thalamus in the phenomenon of confabulations.

-Chafic Karam, MD, and Robert C. Griggs, MD

\section{LETTER RE: LONG-TERM CORTISOL MEASURES PREDICT ALZHEIMER DISEASE RISK}

Simona Lattanzi, Mauro Silvestrini, Ancona, Italy: We read with interest the article by Ennis et al., ${ }^{1}$ which found cortisol dysregulation to be related to an increased risk for Alzheimer disease (AD), and built on the unresolved question of whether systemic homeostasis primarily contributes to $\mathrm{AD}$ expression or represents an epiphenomenon of the underlying brain pathology. Additional considerations might provide useful insights toward a better and more comprehensive understanding of this issue. Within their pleiotropic effects, corticosteroids can greatly influence metabolic functions as well as blood pressure levels and fluctuations, all of which play key roles in dementia onset and course. ${ }^{2}$ In the CNS, corticosteroid receptors are not uniformly localized and abnormal glucocorticoid signaling can result in cell type and site-specific differences. $^{3}$ Accordingly, it would be of great interest to address the interrelationships among cortisol dysregulation, insulin resistance, and blood pressure variability, ${ }^{4}$ and to investigate the associations between cortisol exposure and the risk of nonAD dementias. ${ }^{5}$

1. Ennis GE, An Y, Resnick SM, et al. Long-term cortisol measures predict Alzheimer disease risk. Neurology 2017; 88:371-378.
WriteClick ${ }^{\circledR}$ Editor's Choice

2. Lattanzi S, Luzzi S, Provinciali L, Silvestrini M. Blood pressure variability predicts cognitive decline in Alzheimer's disease patients. Neurobiol Aging 2014;35:2282-2287.

3. Herman JP. Regulation of adrenocorticosteroid receptor mRNA expression in the central nervous system. Cell Mol Neurobiol 1993;13:349-372.

4. Lattanzi S, Viticchi G, Falsetti L, et al. Visit-to-visit blood pressure variability in Alzheimer disease. Alzheimer Dis Assoc Disord 2014;28:347-351.

5. Lattanzi S, Luzzi S, Provinciali L, Silvestrini M. Blood pressure variability in Alzheimer's disease and frontotemporal dementia: the effect on the rate of cognitive decline. J Alzheimers Dis 2015;45:387-394.

(C) 2017 American Academy of Neurology

\section{AUTHOR RESPONSE: LONG-TERM CORTISOL MEASURES PREDICT ALZHEIMER DISEASE RISK} Scott D. Moffat, Atlanta: I thank Drs. Lattanzi and Silvestrini for the thoughtful response to our article. ${ }^{1}$ I fully agree with their suggested mechanisms of action by which cortisol may increase risk for $\mathrm{AD}$. In our sample, we had very few non-AD dementias, which precluded a more comprehensive assessment of how cortisol dysregulation may affect risk for other dementias, though it is a fascinating question.

1. Ennis GE, An Y, Resnick SM, et al. Long-term cortisol measures predict Alzheimer disease risk. Neurology 2017; 88:371-378.

(C) 2017 American Academy of Neurology

\section{LETTER RE: MEDIODORSAL NUCLEUS AND ITS MULTIPLE COGNITIVE FUNCTIONS}

Marco Onofrj, Chieti, Italy: The review on mediodorsal (thalamic) nucleus by Golden et al. ${ }^{1}$ omitted referencing relevant information. Mediodorsal nucleus was the focus of a historic debate on the origin of confabulations in Korsakoff syndrome, ${ }^{2-4}$ which is characterized by confabulations (beyond amnesia) only if mediodorsal nuclei are involved. ${ }^{2-4}$ Clinical findings observed in isolated lacunes of mediodorsal nuclei could elucidate the point, yet isolated lacunes, like the one described in the representative case, ${ }^{1}$ are extraordinarily rare.

I recently described one case with confabulations due to isolated bilateral and symmetric lacunes of 
mediodorsal nuclei where connectivity could also be studied. ${ }^{5}$ In this report, ${ }^{5}$ the possible role of projections to medial prefrontal cortex, node of the anterior default mode network associated with self-referential narrative, was underlined (same as in the review by Golden et al.). The omission of considering confabulations in the review may be due to the fact that the representative case described did not have confabulations. ${ }^{1}$ However, the patient's lesions were only in the left mediodorsal nucleus, ${ }^{1}$ while from analysis of my patient and discussion of the only 5 documented cases, a key role emerged for the right mediodorsal nuclei (or bilaterality) in the genesis of thalamic confabulations. ${ }^{5}$

1. Golden EC, Graff-Radford J, Jones DT, Benarroch EE Mediodorsal nucleus and its multiple cognitive functions. Neurology 2016;87:2161-2168.

2. Victor M, Adams RD, Collins GH. The WernickeKorsakoff Syndrome. Philadelphia: FA Davis; 1971.

3. Mair WG, Warrington EK, Weiskrantz L. Memory disorder in Korsakoff's psychosis: a neuropathological and neuropsychological investigation of two cases. Brain 1979;102:749-783.

4. Signoret JL. Memory and amnesias. In: Mesulam MM, ed. Principles of Behavioral Neurology. Philadelphia: FA Davis; 1985:169-192.

5. Onofrj V, Delli Pizzi S, Franciotti R, et al. Medio-dorsal thalamus and confabulations: Evidence from a clinical case and combined MRI/DTI study. Neuroimage Clin 2016;12: 776-784.

C 2017 American Academy of Neurology

AUTHOR RESPONSE: MEDIODORSAL NUCLEUS AND ITS MULTIPLE COGNITIVE FUNCTIONS

Erin C. Golden, Jonathan Graff-Radford, David T. Jones, Eduardo E. Benarroch, Rochester, MN: We thank Dr. Onofrj for the comments on our review, ${ }^{1}$ and for highlighting past literature that suggested the mediodorsal nucleus of the thalamus may also be involved in the development of confabulations in addition to the clinical features described in our case of an isolated left-sided lesion. Indeed, Dr. Onofrj's group's recent clinical case of bilateral lesions of the mediodorsal thalamic nuclei and the associated imaging data lend further support to this concept. Their study and case series would interestingly suggest a possible laterality to the role of the thalamus in the phenomenon of confabulations and provide valuable groundwork for future study in this area.

1. Golden EC, Graff-Radford J, Jones DT, Benarroch EE. Mediodorsal nucleus and its multiple cognitive functions. Neurology 2016;87:2161-2168.

(C) 2017 American Academy of Neurology

\section{CORRECTIONS}

Prespecified dose-response analysis for A Very Early Rehabilitation Trial (AVERT)

In the article "Prespecified dose-response analysis for A Very Early Rehabilitation Trial (AVERT)" by J. Bernhardt et al., there was an error in the Creative Commons (CC) license statement. The article, funded by NIHR, should have published with a CC-BY license rather than a CC BY-NC-ND license. An article with the corrected license statement was republished on June 5, 2017. The authors regret the error.

\section{REFERENCE}

1. Bernhardt J, Churilov L, Ellery F, et al. Prespecified dose-response analysis for A Very Early Rehabilitation Trial (AVERT). Neurology 2016;86:2138-2145.

Decrease in A $\mathbf{A} 42$ predicts dopa-resistant gait progression in early Parkinson disease

The article "Decrease in A 342 predicts dopa-resistant gait progression in early Parkinson disease" by L. Rochester et al., ${ }^{1}$ funded by Parkinson's UK (COAF Partnership), should have published with the Creative Commons Attribution License (CC BY). The article with the corrected license statement was republished on June 3, 2017. The authors regret the error.

\section{REFERENCE}

1. Rochester L, Galna B, Lod S, et al. Decrease in A 342 predicts dopa-resistant gait progression in early Parkinson disease. Neurology 2017;88:1501-1511. 